\title{
A case of nasopharyngeal angiofibroma removed using a minimally invasive endoscopic endonasal technique
}

\author{
Ji Sun Kim¹, Dong-Hyun Kim², Eun-Ju Jeon², Byung Guk Kim ${ }^{1}$ \\ ${ }^{1}$ Department of Otorhinolaryngology-Head and Neck Surgery, St. Paul's Hospital, The Catholic University of Korea, Seoul, South Korea \\ 2Department of Otorhinolaryngology-Head and Neck Surgery, Incheon St. Mary's Hospital, The Catholic University of Korea, Seoul, \\ South Korea
}

Videosurgery Miniinv 2018; 13 (4): 551-555

DOI: https://doi.org/10.5114/wiitm.2018.75862

\begin{abstract}
Nasopharyngeal angiofibroma is a rare head and neck tumor characterized by hypervascularity. With the development of various surgical devices and hemostatic agents, endoscopic endonasal surgery for nasopharyngeal angiofibroma, which is characterized by significant intraoperative bleeding, has become possible. We describe our experiences performing an effective endoscopic endonasal removal of a nasopharyngeal angiofibroma without embolization, using advanced devices and hemostatic agents. A 21-year-old male patient presented with massive epistaxis. The characteristic findings of angiofibroma were confirmed by computed tomography scan and nasal endoscopy. Navigation-guided endoscopic endonasal surgery was performed, and complementary devices and products were used to effectively remove the mass. Development of navigation, endoscopes, tissue handling devices, and hemostatic agents has enabled effective endoscopic endonasal removal of nasopharyngeal angiofibroma without embolization.
\end{abstract}

Key words: endoscopes, angiofibroma, nasopharyngeal, hemostatic, device.

\section{Introduction}

Nasopharyngeal angiofibroma is a rare, benign tumor that accounts for $0.05 \%$ to $1 \%$ of head and neck tumors [1]. It is histologically benign but can expand aggressively into surrounding structures and has a relatively high recurrence rate. Surgical removal is a primary treatment, and in recent years, endoscopic removal of nasopharyngeal angiofibroma has been more common because of the development of various endoscopes and instruments. When endoscopically removing a nasopharyngeal angiofibroma, minimization of bleeding is imperative in order to optimize visualization and to decrease complications. Thus, most nasopharyngeal angiofibroma removal has been performed using embolization of feeding vessels to reduce the typically massive intraoperative bleeding. However, there is a risk of complications from the transfer of embolic material. Thus, we describe herein our experiences with treating a patient with nasopharyngeal angiofibroma, which was successfully removed using a minimally invasive endoscopic endonasal technique with navigation guidance and without embolization. We describe this case and review the literature.

\section{Case report}

A 21-year-old male patient visited our clinic with a large volume of nasal bleeding. The patient had no underlying disease and took no medications. On nasal endoscopy, a smooth, hypervascular mass filled the right posterior nasal cavity. On paranasal sinus computed tomography scan with contrast

\section{Address for correspondence}

Prof. Dong-Hyun Kim PhD, Department of Otorhinolaryngology-Head and Neck Surgery, Incheon St. Mary’s Hospital, College of Medicine, The Catholic University of Korea, Seoul, South Korea, phone: +82 018788 5475, e-mail: monolithkim@catholic.ac.kr 
enhancement, a $4 \times 2 \times 3 \mathrm{~cm}$ mass was seen in the right posterior nasal cavity and nasopharynx, with a definite boundary and without invasion into the surrounding structures (e.g., sphenoid sinus and pterygopalatine fossa) (Photos 1 A, B). Medially, the mass was adjacent to the nasal septum; laterally, it was adjacent to the inferior turbinate; posteriorly, it occupied the nasopharynx. Preoperative catheter angiography revealed that the feeding vessels were mainly branched from the right maxillary artery (Photo $1 \mathrm{C}$ ). Embolization was not performed because of the risk of complications from the embolic material. Fusion ENT Navigation (Medtronic, Jacksonville, FL, USA) guided endoscopic surgery was performed under general anesthesia. Evac 70

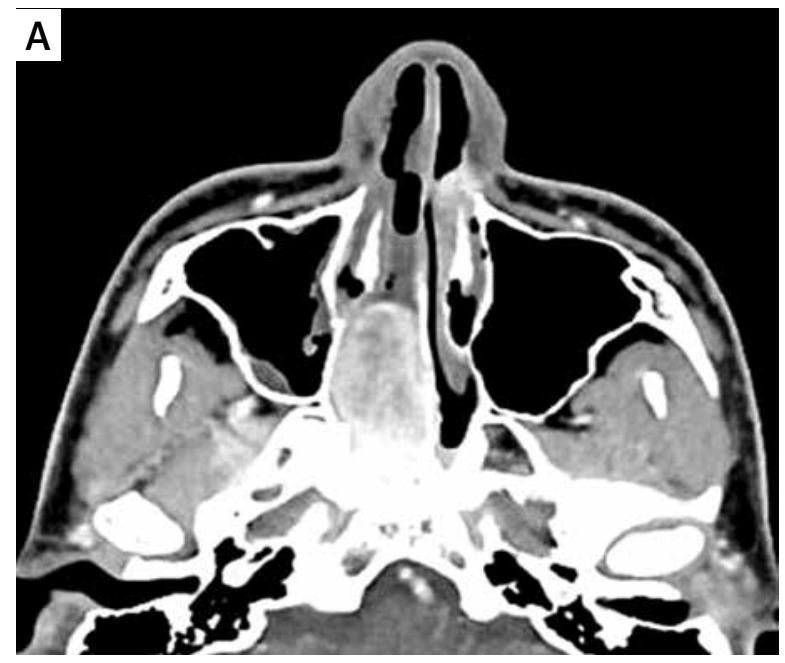

C

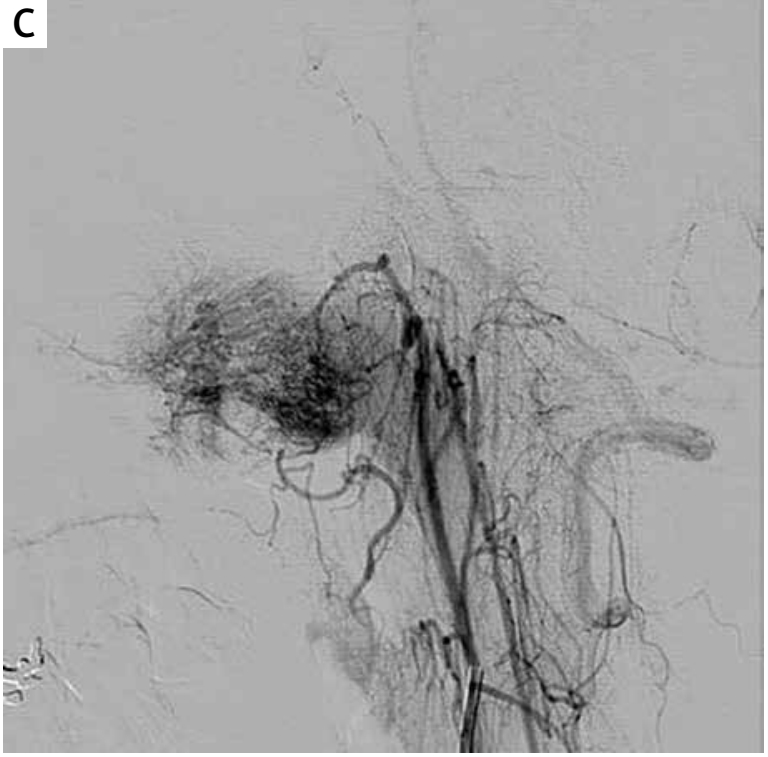

(ArthroCare Corp., Sunnyvale, CA, USA) was used to resect the mass and to control its bleeding (Photo 2 A). Mass excision was also performed using Harmonic ACE Shears (Ethicon Endo-Surgery, Inc., Cincinnati, Ohio, USA), which were used to perform transection and simultaneous coagulation of tissues and vessels, especially around the mass near the sphenopalatine foramen (Photo 2 B). En bloc resection of the mass was completed, and no residual mass was found. TachoComb (CSL Behring, Tokyo, Japan) was applied to the residual bleeding site from which the mass was removed, and Tisseel (Baxter Healthcare Corporation, Deerfield, IL, USA) was also applied. Total operation time was about $90 \mathrm{~min}$, and intraoperative bleeding was approxi-

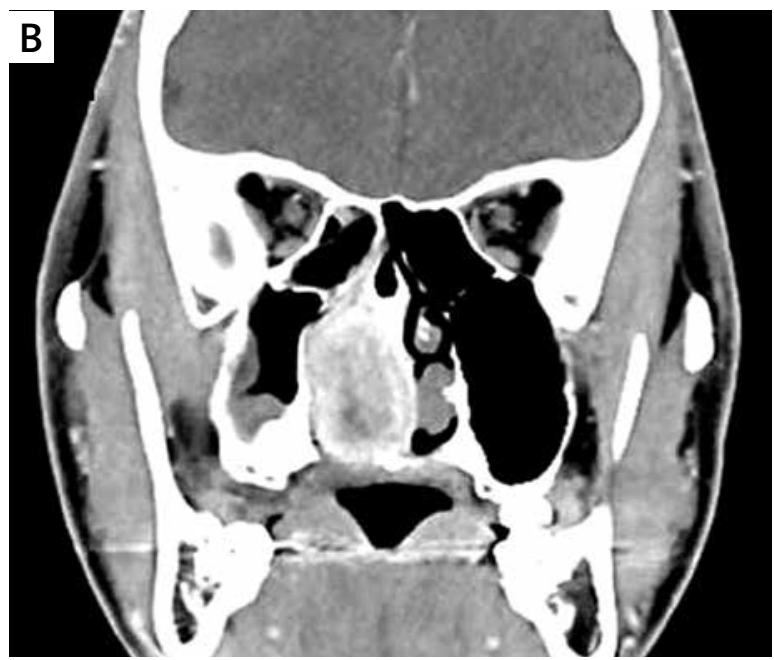

Photo 1. Preoperative computed tomography imaging with contrast enhancement and catheter angiography. Axial (A) and coronal (B) scans show a low-density soft mass with heterogeneous enhancement occupying the nasopharynx and nasal cavity. This mass was also in contact with the septum. Catheter angiography (C) showed feeding vessels supplying blood to the mass 

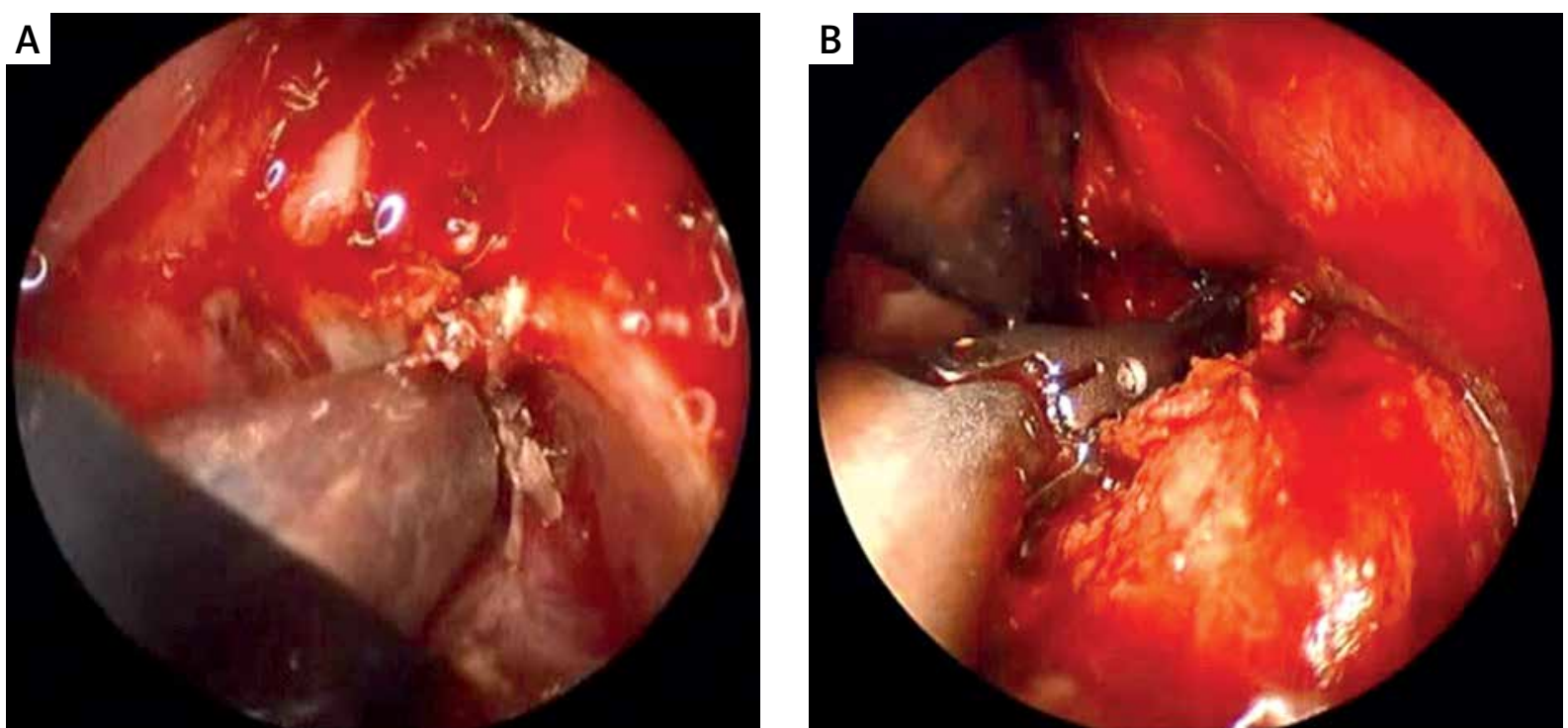

Photo 2. Endoscopic view of the radiofrequency coblation-assisted excision (A) and dissection with harmonic scalpel (B) of the nasopharyngeal angiofibroma prior to en bloc resection

mately $700 \mathrm{ml}$. At 10 months postoperatively, there was no recurrence or complications.

\section{Discussion}

The primary treatment for nasopharyngeal angiofibroma is surgical resection. Previously, removal was performed using an external approach, such as midfacial degloving and lateral rhinotomy. Recently, endoscopic resection of nasopharyngeal angiofibroma has become possible because of technological developments. Because nasopharyngeal angiofibroma has a high likelihood of recurrence, it is important to identify its origin and to remove it completely. The endoscopic system allows us to visualize the angiofibroma origin more clearly than the naked eye. There have been reports of many advantages of endoscopic resection over an external approach, including reduced intraoperative bleeding and recurrence rate [2, 3].

The major disadvantage of endoscopic surgery is that it can be difficult to obtain a field of view because of hemorrhage. Thus, if an endoscope is used to remove a hemorrhagic mass, adequate hemostasis is essential for safe and effective mass removal. Many methods can be used to decrease bleeding during endoscopic removal, including cautery and embolization. For over 40 years, studies of nasopharyngeal angiofibroma have demonstrated techniques to reduce intraoperative bleeding with preop- erative embolization [4, 5]. However, the side effects (e.g., blindness, stroke, and neurologic deficit) may occur as the embolic material is delivered [6-8]. The physician should also be aware of the risks of embolization and the possibility of intraoperative bleeding because of the remaining blood supply after embolization [9]. In endoscopic removal of nasopharyngeal angiofibroma with preoperative embolization, the mean intraoperative blood loss was reported to vary from $350 \mathrm{ml}$ to $800 \mathrm{ml}$ [10-14]. In some studies, endoscopic resection without embolization resulted in less than $500 \mathrm{ml}$ of intraoperative bleeding [15, 16]. These studies differed from ours in that they did not use special instruments other than an electronic coagulator, and additional procedures were performed, such as partial inferior turbinectomy, and ligation of maxillary or sphenopalatine arteries for proper visualization and prevention of hemorrhage. Although there was more blood loss than reported in some articles, our method does not require additional procedures. There was no risk of embolization-related complications. Moreover, there was no additional procedure to control the feeding arteries, and the maxillary wall and surrounding tissues could be preserved.

Radiofrequency coblation uses bipolar radiofrequency-based plasma for adequate tissue removal at relatively low temperatures $\left(40-65^{\circ} \mathrm{C}\right)$, minimizing thermal damage to surrounding tissue, whereas conventional electrosurgical devices operate at tem- 
peratures as high as $400-600^{\circ} \mathrm{C}$. In previous studies using radiofrequency coblation for endoscopic tumor resection, coblation improved the surgical field of view and reduced intraoperative bleeding over conventional coagulation methods $[17,18]$. In our experience, radiofrequency coblation was convenient for performing effective hemostasis, by switching the ablation and coagulation modes. It also had a suction function that allowed dissection while simultaneously removing smoke and blood. We used the Evac 70 model, which was designed for tonsillectomy and adenoidectomy. We expect that this surgical technique would be more easily performed if a small diameter wand, suitable for endoscopic endonasal surgery, were used.

In a procedure where a nasopharyngeal angiofibroma was removed using a coblator without preoperative embolization, when the tumor was separated from the superior choanae, it was difficult to control hemostasis with a coblator in the large vessels at the location [19]. Therefore, we used a complementary harmonic scalpel and could achieve sufficient hemostasis near the sphenopalatine foramen. The harmonic scalpel is an ultrasonic dissector used in a variety of surgical fields. This device has the advantage of being able to grasp and manipulate tissue precisely. Radiofrequency coblation is performed with ablation and coagulation separately, but a harmonic scalpel can be used to perform transection simultaneously with coagulation of tissues and vessels, thereby reducing operating time. One previous study using an older-generation harmonic scalpel to remove angiofibroma reported difficulties with controlling bleeding [14]. However, recent developments allow handling of vessels of various thicknesses up to $7 \mathrm{~mm}$, depending on the model. The Harmonic ACE Shears used in this case can resect vessels up to $5 \mathrm{~mm}$ thick. This was useful for dissection of the mass, on which it was difficult to perform hemostasis with radiofrequency coblation. The harmonic scalpel was also useful for endoscopic surgery because of its thinness and length. However, additional assistance was needed to suction smoke during use of the harmonic scalpel for endoscopic endonasal surgery.

In otolaryngology, a navigation system is used to prevent complications that may occur in endoscopic endonasal procedures. In our case, the navigation helped to confirm and identify the surgical site where the visual field narrowed because of the mass, or when it was difficult to obtain an adequate operative field of view because of hemorrhage. Moreover, we were able to completely remove the nasopharyngeal angiofibroma while confirming its origin through image-guided navigation. Even if there is no invasion of the surrounding tissue, if a mass has the characteristics of hypervascularity, it would be useful to use the navigation system in its endoscopic removal.

There are various hemostatic agents that utilize the clotting mechanism of blood, in which fibrinogen is converted to insoluble fibrin by thrombin. TachoComb is used in a variety of surgical fields, ranging from large bleeding because of surgery or trauma, to low pressure bleeding [20]. Tisseel was originally developed as a medical adhesive but also has good hemostatic effects and can help with wound healing [21]. We used both hemostatic agents to control residual hemorrhage, and these were readily available at sites that could not be approached by devices such as the harmonic scalpel and coblator. These hemostatic agents were especially helpful in controlling bone bleeding and hemorrhage of blood vessels hidden in bone.

Our case suggests that endoscopic endonasal removal of a hypervascular mass, such as a nasopharyngeal angiofibroma, can be performed using advanced devices and products without risk of embolization. Our procedure resulted in an additional cost of about $\$ 1,500$, similar to that of embolization. Further advanced devices and products will be developed. While it is necessary to consider insurance systems and costs for each country, operators should consider using complementary devices to reduce bleeding and operative time, and to avoid complications.

\section{Conclusions}

Using various and complementary devices and products, endoscopic surgery on a hemorrhagic mass can be performed effectively and efficiently.

\section{Conflict of interest}

The authors declare no conflict of interest.

\section{References}

1. Huang Y, Liu Z, Wang J, et al. Surgical management of juvenile nasopharyngeal angiofibroma: analysis of 162 cases from 1995 to 2012. Laryngoscope 2014; 124: 1942-6. 
2. Onerci TM, Yucel OT, Ogretmenoglu O. Endoscopic surgery in treatment of juvenile nasopharyngeal angiofibroma. Int J Pediatr Otorhinolaryngol 2003; 67: 1219-25.

3. Boghani Z, Husain Q, Kanumuri VV, et al. Juvenile nasopharyngeal angiofibroma: a systematic review and comparison of endoscopic, endoscopic-assisted, and open resection in 1047 cases. Laryngoscope 2013; 123: 859-69.

4. Davis KR. Embolization of epistaxis and juvenile nasopharyngeal angiofibromas. AJR Am J Roentgenol 1987; 148: 209-18.

5. Pletcher JD, Newton TH, Dedo HH, et al. Preoperative embolization of juvenile angiofibromas of the nasopharynx. Ann Oto Rhinol Laryngol 1975; 84: 740-6.

6. Casasco A, Houdart E, Biondi A, et al. Major complications of percutaneous embolization of skull-base tumors. AJNR Am J Neuroradiol 1999; 20: 179-81.

7. Loon NW, Gendeh BS, Zakaria R, et al. Ophthalmic artery occlusion following neuro-embolization of the external carotid artery, a case report. BMC Ophthalmol 2017; 17: 92.

8. Soong HK, Newman SA, Kumar AA. Branch artery occlusion. An unusual complication of external carotid embolization. Arch Ophthalmol 1982; 100: 1909-11.

9. Snyderman CH, Pant H, Carrau RL, et al. A new endoscopic staging system for angiofibromas. Arch Otolaryngol Head Neck Surg 2010; 136: 588-94.

10. Ardehali MM, Samimi Ardestani SH, Yazdani N, et al. Endoscopic approach for excision of juvenile nasopharyngeal angiofibroma: complications and outcomes. Am J Otolaryngol 2010; 31: 343-9.

11. Khoueir N, Nicolas N, Rohayem Z, et al. Exclusive endoscopic resection of juvenile nasopharyngeal angiofibroma: a systematic review of the literature. Otolaryngol Head Neck Surg 2014; 150: 350-8.

12. Roger G, Tran Ba Huy P, Froehlich P, et al. Exclusively endoscopic removal of juvenile nasopharyngeal angiofibroma: trends and limits. Arch Otolaryngol Head Neck Surg 2002; 128: 928-35.

13. Tseng HZ, Chao WY. Transnasal endoscopic approach for juvenile nasopharyngeal angiofibroma. Am J Otolaryngol 1997; 18 : 151-4.

14. Ochi K, Watanabe S, Miyabe S. Endoscopic transnasal resection of a juvenile angiofibroma using an ultrasonically activated scalpel. ORL J Otorhinolaryngol Relat Spec 2002; 64: 290-3.

15. El Sharkawy AA. Endonasal endoscopic management of juvenile nasopharyngeal angiofibroma without angiographic embolization. Eur Arch Otorhinolaryngol 2013; 270: 2051-5.

16. Fyrmpas G, Konstantinidis I, Constantinidis J. Endoscopic treatment of juvenile nasopharyngeal angiofibromas: our experience and review of the literature. Eur Arch Otorhinolaryngol 2012; 269: 523-9.

17. Kostrzewa JP, Sunde J, Riley KO, et al. Radiofrequency coblation decreases blood loss during endoscopic sinonasal and skul base tumor removal. ORL J Otorhinolaryngol Relat Spec 2010; 72: 38-43.

18. Syed MI, Mennie J, Williams AT. Early experience of radio frequency coblation in the management of intranasal and sinus tumors. Laryngoscope 2012; 122: 436-9.

19. Ruiz JW, Saint-Victor S, Tessema B, et al. Coblation assisted endoscopic juvenile nasopharyngeal angiofibroma resection. Int J Pediatr Otorhinolaryngol 2012; 76: 439-42.
20. Agger P, Langhoff J, Smerup MH, et al. Comparison between TachoComb and TachoSil for surgical hemostasis in arterial bleeding: an animal experimental study. J Trauma 2010; 68: 838-42.

21. Saltz R, Sierra D, Feldman D, et al. Experimental and clinical applications of fibrin glue. Plastic Reconstr Surg 1991; 88: 1005-15.

Received: 17.03 .2018 , accepted: 7.04.2018. 